
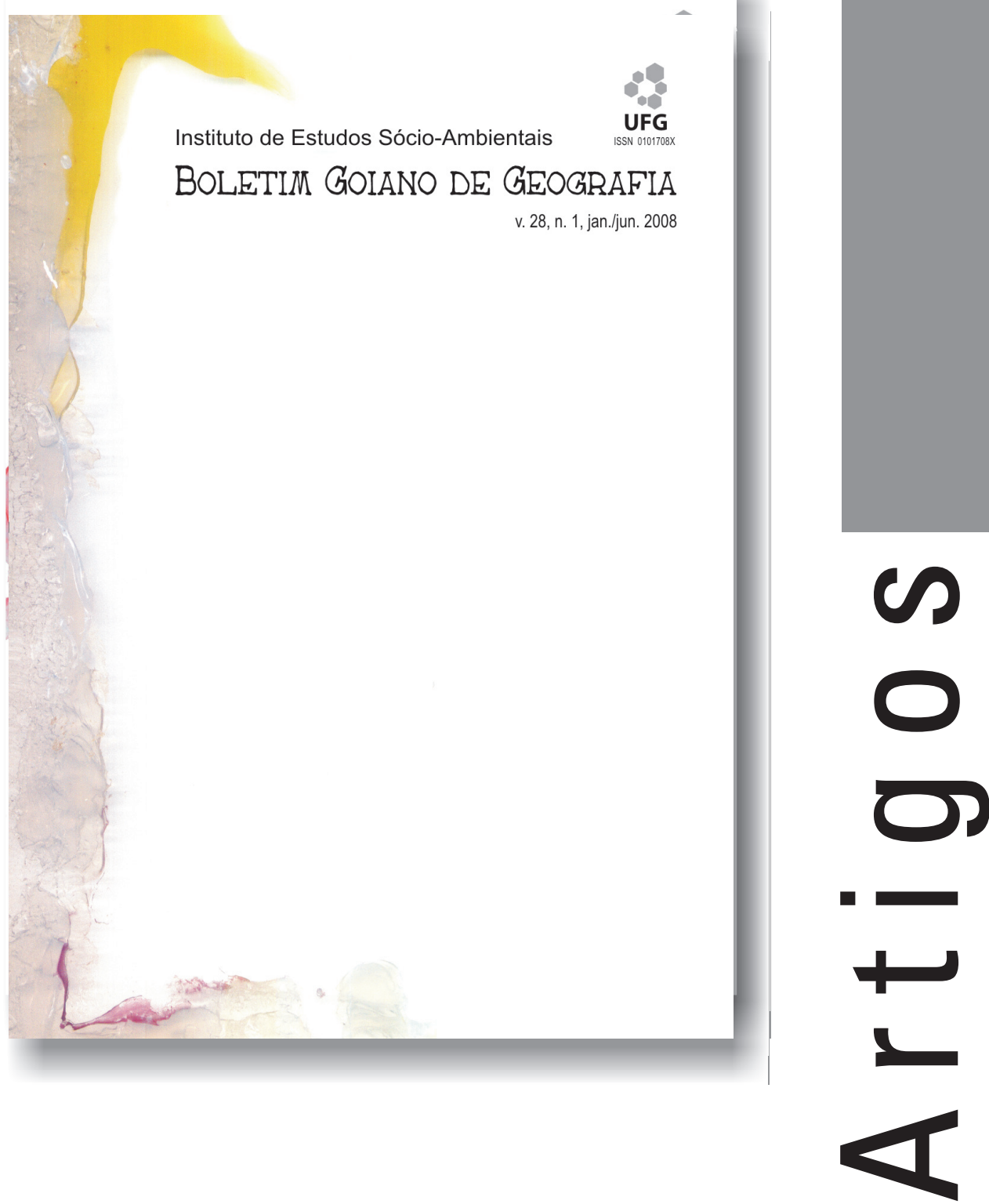


\title{
Técnicas de sensoriamento remoto aplicadas à biogeografia: metodologia geográfica para espacialização de moluscos terrestres
}

\author{
Techniques of remote sensing apply in biogeography: geographic methodological to terrestrial \\ mollusks espacialization
}

Thiago Morato de Carvalho - Universidade Federal de Goiás

tmorato@infonet.com.br

Rina Ramirez - Universidad Nacional Mayor de San Marcos, Lima, Perú

rramirez@yahoo.com

\section{Resumo}

Este artigo tem como objetivo aplicar algumas técnicas de sensoriamento remoto, como produtos topográficos para interpretação da biogeografia de onze espécies de moluscos terrestres em Lima, Peru. A metodologia consistiu em técnicas de sensoriamento remoto e geoprocessamento para a elaboração de mapas de localização e produtos topográficos, como declividade, hipsometria e perfis topográficos para análises geoespacial.

Palavras-chave: sensoriamento remoto, Lima, Peru, SRTM, moluscos, biogeografia

\begin{abstract}
The aim of this work was apply some technical in remote sensing, like topographic products for the interpretation of the biogeography of the eleven species of land mollusks in the area of Lima, Peru. The methodology was based in geoprocessing and remote sensing techniques to make localization maps and relief products from SRTM images like slope, density slice and topographic profiles of the land surface for geospatial analyses.
\end{abstract}

Key-words: remote sensing, Lima, Peru, SRTM, mollusks, biogeography 


\section{Introdução}

Existem dois mecanismos principais que podem determinar a evolução das espécies, estes são: a variabilidade genética e a seleção natural. No entanto, este esquema necessita ser complementado com outro fator determinante que é a especiação geográfica. A distribuição dos animais terrestres é correlacionada com as grandes formações vegetais e a temperatura. No entanto, estes dois grandes fatores dependem das características topográficas, seja em escala regional ou continental.

Para este tipo de estudo em que se faz uso da correlação das espécies com a geografia, denomina-se de Biogeografia, em que biólogos e geógrafos têm trabalhado em conjunto de forma interdisciplinar, no intuito de gerar melhores conhecimentos à zoogeografia e às questões paleoclimáticas, como pude acompanhar pessoalmente às atividades de dois amigos Vanzolini e Aziz.

Ao longo das últimas décadas, desde 1970, as metodologias empregadas em estudos ambientais sofreram grande impacto com novas tecnologias, maior agilidade, objetividade, consistência e precisão na tomada de decisões geoespaciais. O processamento de informações geográficas nos dias de hoje é uma atividade fundamental nas análises qualitativas e quantitativas na caracterização do objeto de estudo. Recentemente, produtos como da Shuttle Radar Topography Mission (SRTM) têm-se tornado ferramentas indispensáveis na caracterização geoambiental, estes produtos de imagens de radar se distinguem dos anteriores por serem de visada vertical e lateral, logo são capazes de reproduzir em três dimensões o relevo, são considerados imagens de radar por terem sido obtidos através de dois sensores de radar (Bandas $\mathrm{C}$ e X) por interferometria. A interferometria é o método em que permite obter informações da altitude do relevo, ou seja, nos fornece um modelo digital do terreno (MDT), sendo assim, as imagens da SRTM são denominadas de imagens IfSAR (Interferometric Synthetic Aperture Radar), ou simplesmente, imagens SRTM.

O uso das imagens SRTM tem se tornado cada vez mais freqüente em estudos geológicos, hidrológicos, geomorfológicos, ecológicos, dentre outros, em particular para análises tanto quantitativas como qualitativas do relevo e seus agentes modificadores (Carvalho, 2003; Carvalho 2004; Carvalho, 2007; Alves e Carvalho, 2007), em especial na elaboração de mapas hipsométricos e clinográficos (declividade) e de perfis topográficos, dentre outros produtos elaborados a partir de variáveis relacionadas à topografia.

O presente estudo foi parte de um trabalho de doutorado sobre biogeografia de moluscos terrestres da costa central do Peru, cuja multidiscipli- 
naridade envolve os campos da geografia e biologia e pretende aqui divulgar como forma de um artigo sucinto a temática da biogeografia.

\section{Área de estudo}

A área amostrada corresponde ao centro da cidade capital do Peru, Lima, e a maior ilha na costa do Peru, Ilha San Lorenzo (Figura 1). No continente, a maior extensão do terreno está habitado, ficando apenas os sopés e os picos dos Andes. Na cidade de Lima foram estudas áreas inabitadas, como o Morro Solar e os Cerros San Cristobal com altitude de 400m, Observatório Alto, altitude de 465m, e Cerro Segundo com 520m, morros dos sopés dos Andes (área de encostas). O clima da região é desértico subtropical, onde a biodiversidade desenvolve-se nos ecossistemas de "lomas" sustentados pelas névoas marinhas (Oka \& Ogha, 1984; Ono, 1986).

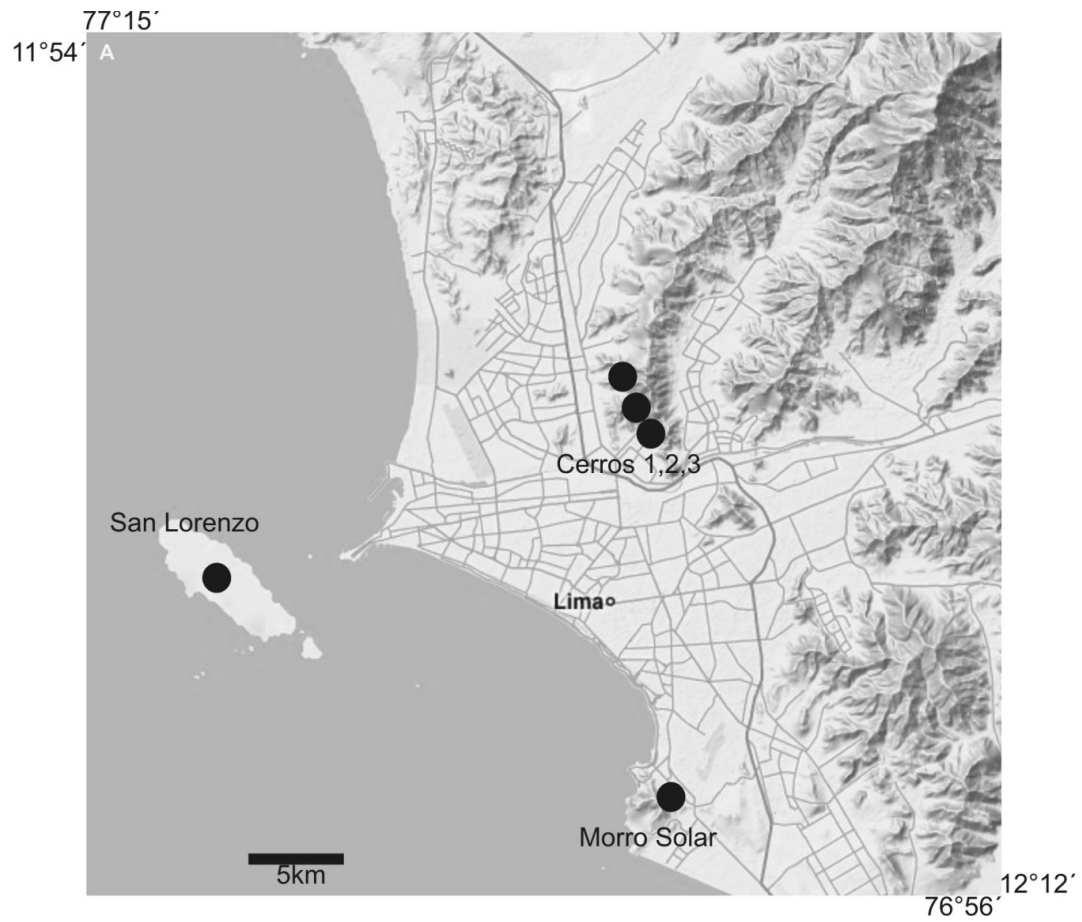

Figura 1 - Localização da área de estudo, os círculos em preto representam as áreas de coleta. Cerros 1,2,3 são respectivamente Observatório Alto, Segundo e San Cristobal. 


\section{Materiais e métodos}

Para a elaboração dos produtos cartográficos, como mapa de localização, modelo digital do terreno (MDT), mapa de declividade, hipsometria, perfis topográficos, e plotagem da distribuição dos moluscos terrestres, foi necessário o uso de softwares, como o ENVI 4.1 e CartaLinx. Os produtos acima citados tiveram como base cartográfica a carta topográfica 25-i (Lima, Peru) do Instituto Geográfico Nacional do Peru, na escala 1:100.000 e imagens da SRTM no formato HGT (height). Para a elaboração da carta temática de localização foi necessária a digitalização da carta topográfica para ser georeferenciada no ENVI 4.1, cada intersecção das quadrículas passou a ser um ponto de controle, registrados como UTM, fuso 18 sul, SAD69, assim como a imagem SRTM. Após o registro da carta o método para o procedimento de warp file foi polinomial por vizinho mais próximo. $\mathrm{O}$ arquivo gerado foi exportado em formato geo-tiff, e após, importado para o software CartaLinx. Foram vetorizadas as cidades, estradas e vegetação. As imagens SRTM foram mosaicadas, das quais se geraram alguns produtos como imagem sombreada, hipsometria, declividade e alguns perfis topográficos. Estes produtos foram importados no CartaLinx para plotagem das localidades dos moluscos terrestres e finalização dos mapas de ocorrência. As localizações das espécies de moluscos terrestres foram registradas com o uso de GPS na região de Lima, Peru, estes já descritos pela equipe de pesquisadores do instituto de biologia da Universidade Católica do Peru. A região de amostragem escolhida foi a Ilha de San Lorenzo e áreas de encostas de morros dos sopés dos Andes na região metropolitana de Lima, por serem áreas desabitadas e com encostas voltadas para os ventos alísios.

\section{Resultados e discussão}

O fator principal para que haja a distribuição diferenciada das espécies de moluscos terrestres na região metropolitana de Lima é a variação topográfica, pois esta serve de obstáculo à névoa deslocada do oceano pelos ventos alísios na direção geral W-E. Esta névoa, quando desloca-se pelos sopés (encosta) dos Andes sofre ascensão e precipita-se, principalmente e com maior abrangência, em áreas elevadas como nos morros Observatório Alto, Segundo e San Cristobal, entre as cotas 150 a 750 metros. Nesta região de barlavento, desenvolve-se nas escarpas uma vegetação herbácea estacio- 
nal que vigora durante o inverno com as névoas que vêm do mar, mas que durante os eventos El Niño podem vigorar também no verão, devido às anormalidades de precipitação pluvial (OBREGÓN et al, 1985).

O Morro Solar, ao sul da cidade de Lima, com cotas variando de 0 a 278 metros, está junto à linha de praia e tem vegetação xerofítica dominada por uma espécie Tillandisia latifolia. A precipitação de névoa não é significante nesta área, pois se trata de um morro isolado, e ao contrário das encostas dos Andes, ela não possui obstáculos para se estabilizar e favorecer a precipitação.

A ilha San Lorenzo apresenta um aspecto desértico (árido), com pico máximo de 90 metros, a $5 \mathrm{~km}$ do continente, está posicionada na direção NO-SE, sendo a sua metade sul dominada por vegetação xerofítica denominada T. latifolia entre as cotas 0 a 24 metros. No sul da ilha a sua maior elevação é de 90 metros, posição estratégica em relação aos ventos alísios, recebendo mais influência das névoas, favorecendo assim, melhores condições de reter umidade, ambiente favorável ao desenvolvimento das duas espécies de moluscos da ilha.

Neste contexto, encontramos as onze espécies de moluscos terrestres distribuídas conforme a tais características morfoclimáticas, ou seja, acidentes topográficos e diferenciação de temperatura de acordo com a altitude influenciada pela umidade. As distribuições das espécies, de forma geral, estiveram relacionadas com a vertente das encostas voltadas para os ventos alísios (posição de barlavento), isso é explicado pelo fato de dependerem da umidade das névoas e formação de vegetação nestas áreas. A concentração de moluscos terrestres aumentou nas áreas de maior declividade, em que variou de 5 a 13 graus na ilha de San Lorenzo, 15 a $28^{\circ}$ nas encostas do morro Solar, e 18 a 30 graus no sopé dos Andes (morros Observatório Alto, Segundo e San Cristobal). A figura 2 mostra a posição em que as espécies de moluscos se distribuem nas encostas.

Na Ilha de San Lorenzo ocorrem somente duas espécies de moluscos terrestres, por ser um local desfavorável à retenção de umidade e à formação de vegetação. No continente encontra-se a maior quantidade de espécies nos sopés dos Andes, local favorável a retenção de umidade, onde ocorrem maiores precipitação favorecendo a formação de vegetação e a proliferação de moluscos terrestres (Figura 3). As espécies encontradas foram as seguintes: a) na Ilha San Lorenzo são: Bostryx conspersus e B. laurentii; b) no Morro Solar: B. modestus, Succinea peruviana, Pupoides paredesii e Gastrocopta pazi; c) no sopé dos Andes (morros Observatório Alto, Segundo e San Cris- 
tobal): B. sordidus, B. aguilari, B. conspersus, Scutalus proteus, Succinea peruviana, Wayampia trochilioneides e Heterovaginina limayana.
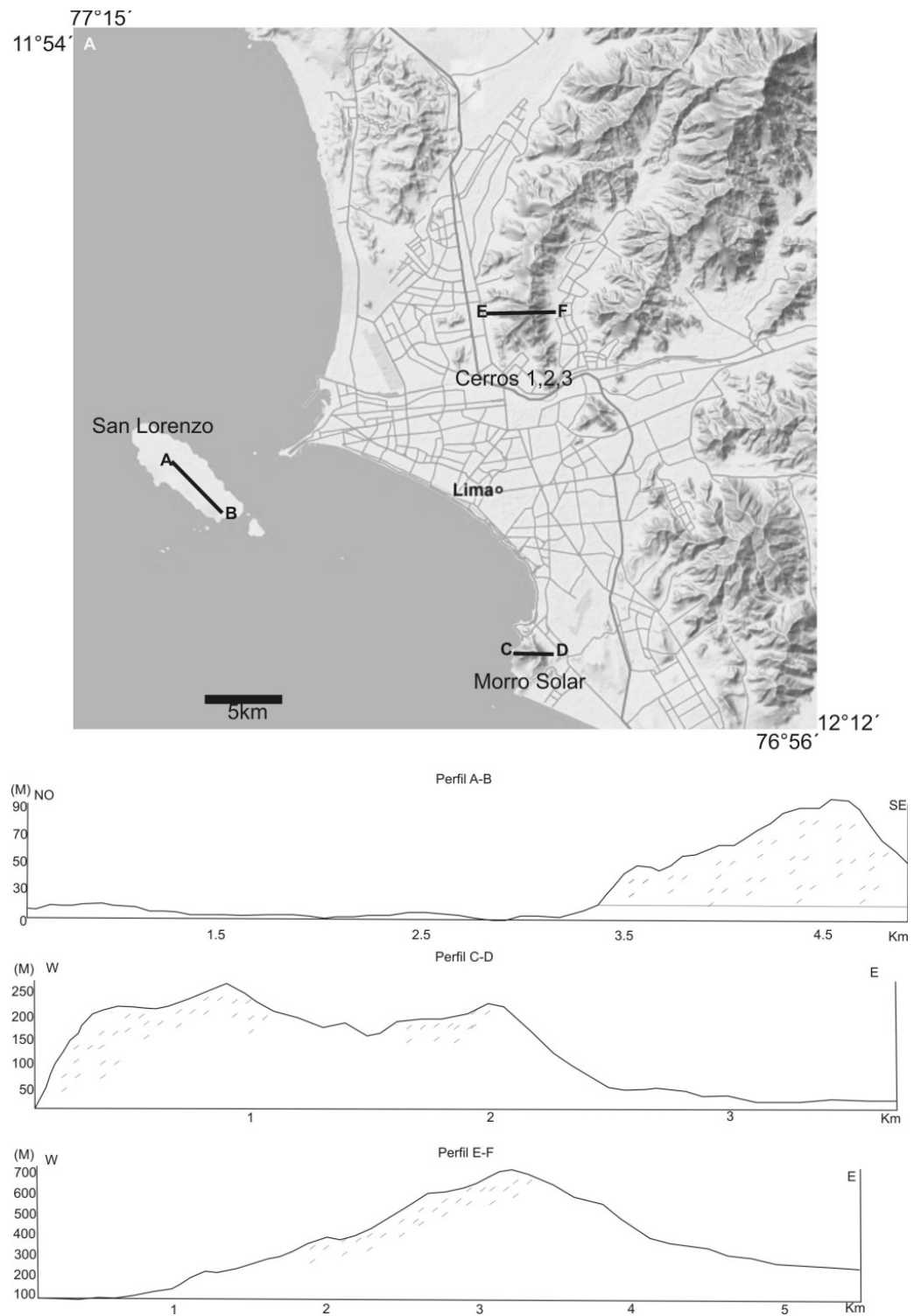

Figura 2 - Perfis topográficos e distribuição das espécies de moluscos terrestres nas encostas de barlavento. A distribuição dos moluscos está indicada pelas áreas hachuradas. 


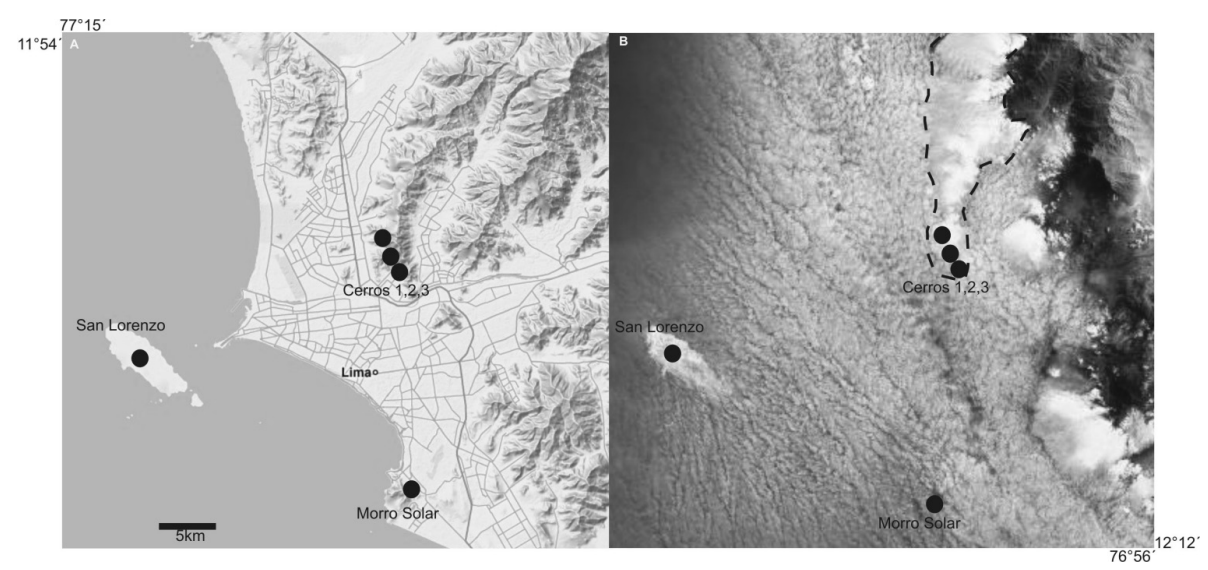

Figura 3 - A figura A indica nos círculos em preto as áreas de ocorrências dos moluscos terrestres; na figura B pode-se observar em comparativo com a "A" os pontos de ocorrência dos moluscos terrestres e a influência das névoas (fogs). As manchas brancas densas são áreas em que a névoa precipita como marca a linha em pontilhados (sopé dos Andes), fenômeno ocorrido em fevereiro de 2002.

Os produtos gerados para uma correlação espacial da distribuição dos moluscos e distribuição da vegetação foram imagens sombreada, hipsometria, declividade e perfis topográficos. A imagem sombreada foi importante para identificar as características topográficas do relevo, como morros, vales, escarpas e áreas planas. Estas características são importantes para a determinação de como as espécies estão distribuídas e quais as barreiras geográficas que determinam esta distribuição, facilitando assim, com o uso de imagem MDT sombreada, a identificação e mapeamento destes fatores. A hipsometria e declividade determinaram quais são as classes altimétricas que as espécies de moluscos ocorrem e como é a distribuição da vegetação nas diferentes cotas altimétricas, que também implica na variação de temperatura e retenção de umidade. Alguns perfis topográficos foram gerados com a finalidade de melhor identificar os acidentes topográficos, verificando o grau de variedade altimétrica da topografia e a distribuição das espécies.

O sensoriamento remoto resultou de grande importância para evidenciar tais características da área em estudo e relacionar com as distribuições dos moluscos que ocorrem nesta região.

A análise dos produtos confeccionados, em especial recursos de visualização 3D, possibilitou uma melhor análise dos aspectos físicos e biológicos da região. 
O uso de ferramentas apropriadas como o geoprocessamento, tem demonstrado um grande auxílio na análise de dados biogeográficos, como o Modelo Digital do Terreno, que tem sido utilizado há mais de quatro décadas na análise de padrões morfológicos. A combinação dos padrões morfológicos com dados biológicos num MDT tem demonstrado ser um excelente método para a biogeografia, que precisa ser bastante explorado.

\section{Referências}

CARVALHO, T.M. Uso de Modelos Digitais do Terreno para analises geomorfológicas e geológicas: $\mathrm{O}$ caso da Bacia Hidrográfica do rio Araguaia. Monografia, Pontifica Universidade Católica do Rio Grande do Sul, Porto Alegre. 89p. 2003.

CARVALHO, T.M.. Aplicação de Modelos Digitais do Terreno (MDT) em análises macrogeomorfológicas: O caso da Bacia Hidrográfica do Araguaia. Revista Brasileira de Geomorfologia, ano.5, n.1, pg.85-93. 2004.

CARVALHO, T.M. Métodos de sensoriamento remoto aplicados à geomorfologia. Revista Geográfica Acadêmica, volume 1, n.1, pg.44-54. 2007.

ALVES, T.M; CARVALHO, T. M. Técnicas de sensoriamento remoto para classificação e quantificação do sistema lacustre do rio araguaia entre barra do garças e foz do rio cirstalino. Revista Geográfica Acadêmica, volume 1, n.1, pg. 79-94. 2007.

OBREGON, G. , E. CISNEROS \& A. DIA.El fenómeno "El Niño" 82-83 y la alteración térmica en Lima. Pp. 263-278. In: M. Vegas (Ed.): Ciencia, Tecnología y Agresión Ambiental: El Fenómeno El Niño. CONCYTEC, 1985.

OKA, S. \& H. OGAWA. The distribution of lomas vegetation and its climatic environments along the Pacific coast of Peru. Geographical Reports of Tokyo Metropolitan University (19): 113-125, 1984.

ONO, M. Definition, classification and taxonomic significance of the Lomas vegetation. (pp. 5-14). M. ONO (ed.): Taxonomic and Ecological Studies on the Lomas Vegetation in the Pacific Coast of Peru. Reports for Overseas Scientific Survey. Makino Herbarium, Tokyo Metropolitan University, 1986.

SILVA, J. L. B.; Souza, S. F.; Lahm, R. A. Interpoladores em Altimetria: uma quantificação dos resultados. Congresso Brasileiro de Cadastro Técnico Multifinalitário - UFSC, Florianópolis - SC, 1998.

Thiago Morato de Carvalho - Geógrafo, doutorando em Ciências Ambientais da Universidade Federal de Goiás - IESA

Rina Ramirez - Bióloga, da Universidad Nacional Mayor de San Marcos, Lima, Perú 